\title{
DISPOSICIONES CONSTITUCIONALES EN MATERIA ECONÓMICA PARA EL MUNICIPIO EN MÉXICO
}

\author{
Marisol Luna Leal
}

doi: 10.18543/ed-63(2)-2015pp153-172

\begin{abstract}
Sumario: 1 . Planteamiento. 2. Disposiciones CONSTITUCIONALES EN MATERIA ECONÓMICA, FINANCIERA Y TRIBUTARIA PARA EL MUNICIPIO MEXICANO. 3. CONTEXTO ACTUAL. ASPECTOS ECONÓMICOS, FINANCIEROS y tributarios. 4. Algunas RUtas Para la solución 5. Fuentes.
\end{abstract}

\section{PLANTEAMIENTO}

Pocas instituciones en el Estado mexicano poseen una trayectoria sinuosa; son piezas fundamentales en el devenir histórico; en el quehacer público; $\mathrm{y}$, con profundo arraigo en la población, como lo es el municipio. El artículo 115 de la Constitución Política de los Estados Unidos Mexicanos (CPEUM) lo reconoce como la base de la división territorial, y de la organización política y administrativa del Estado; es gobernado por un Ayuntamiento electo de manera popular y directa, integrado por el presidente municipal, así como por el número de síndicos y regidores que determine la ley; y se encuentra investido de personalidad jurídica propia. Tiene a su cargo (fracción III-115 CPEUM) servicios públicos de gran calado para toda población tales como, agua potable, drenaje, alcantarillado, tratamiento y disposición de sus aguas residuales; alumbrado público; limpia, recolección, traslado, tratamiento y disposición final de residuos; mercados y centrales de abasto; panteones; rastros; calles, parques y jardines y su equipamiento; las funciones de seguridad pública -bajo los lineamientos establecidos por el Sistema Nacional de Seguridad Pública-; policía preventiva municipal, y tránsito; así como atri- 
buciones en otras áreas que vía facultades concurrentes o de coordinación mediante diversas reformas a la CPEUM le han sido otorgadas. ${ }^{1}$

La reforma constitucional de 1999 lo reconoció como un nivel de gobierno con autonomía propia, la cual como recordaremos se caracteriza por la facultad de elegir libremente a sus gobernantes; otorgarse la reglamentación ${ }^{2}$

${ }^{1}$ En materia de educación (artículo 3. ${ }^{\circ}$ ); Con el propósito de garantizar el derecho al acceso, disposición y saneamiento de agua para consumo personal y doméstico en forma suficiente, salubre, aceptable y asequible (artículo $4 .^{\circ}$ ). En materia de asentamientos humanos; en materia de protección al ambiente y de preservación y restauración del equilibrio ecológico; en materia de protección civil; en materia de cultura física y deporte; en materia de turismo; en materia de pesca y acuacultura; en materia de fomento y desarrollo sustentable de la actividad cooperativa; en la coordinación de acciones en materia de cultura; $y$, en materia de derechos de niñas, niños y adolescentes, cuyo propósito es velar en todo momento por el interés superior de los mismos y cumpliendo con los tratados internacionales de la materia, de los que México sea parte (artículo 73). Así como propiciar el fortalecimiento del sistema de seguridad social del personal del Ministerio Público, de las corporaciones policiales y de los servicios periciales, de sus familias y dependientes, instrumentarán sistemas complementarios de seguridad social (artículo 123).

2 MUNICIPIOS. CONTENIDO Y ALCANCE DE SU FACULTAD REGLAMENTARIA. A raíz de la reforma constitucional de 1999 se amplió la esfera competencial de los Municipios en lo relativo a su facultad reglamentaria en los temas a que se refiere el segundo párrafo de la fracción II del artículo 115 de la Constitución Política de los Estados Unidos Mexicanos; derivado de aquélla, los Ayuntamientos pueden expedir dos tipos de normas reglamentarias: a) el reglamento tradicional de detalle de las normas, que funciona similarmente a los derivados de la fracción I del artículo 89 de la Constitución Federal y de los expedidos por los Gobernadores de los Estados, en los cuales la extensión normativa y su capacidad de innovación está limitada, pues el principio de subordinación jerárquica exige que el reglamento esté precedido por una ley cuyas disposiciones desarrolle, complemente o pormenorice y en las que encuentre su justificación y medida; y b) los reglamentos derivados de la fracción II del artículo 115 constitucional, que tienen una mayor extensión normativa, ya que los Municipios, respetando las bases generales establecidas por las legislaturas, pueden regular con autonomía aquellos aspectos específicos de la vida municipal en el ámbito de sus competencias, lo cual les permite adoptar una variedad de formas adecuadas para regular su vida interna, tanto en lo referente a su organización administrativa y sus competencias constitucionales exclusivas, como en la relación con sus gobernados, atendiendo a las características sociales, económicas, biogeográficas, poblacionales, culturales y urbanísticas, entre otras, pues los Municipios deben ser iguales en lo que es consustancial a todos - lo cual se logra con la emisión de las bases generales que emite la Legislatura del Estado-, pero tienen el derecho, derivado de la Constitución Federal de ser distintos en lo que es propio de cada uno de ellos, extremo que se consigue a través de la facultad normativa exclusiva que les confiere la citada fracción II. Controversia constitucional 14/2001. Municipio de Pachuca de Soto, Estado de Hidalgo. 7 de julio de 2005. Unanimidad de diez votos. Ausente: José De Jesús Gudiño Pelayo. Ponente: Olga Sánchez Cordero de García Villegas. Secretarias: Mariana Mureddu GilaBERT y CARmina Cortés RodríGuez. Jurisprudencia, P./J. 132/2005, Seminario de la Suprema Corte de Justicia y su Gaceta, novena época, pleno, XXII, octubre 2005, p. 2069. 
que estime adecuada para su organización interior, así como la relativa a atender las problemáticas de sus ámbitos espacial y material; gestionar y resolver los asuntos propios de su población relativos a servicios y funciones públicas; contar con atribuciones en materia tributaria; y ejercer con libertad su hacienda pública. ${ }^{3}$ Como recordaremos para lograr la autonomía plena, es conditio sine qua non la existencia de autonomía en las vertientes política; administrativa; y, financiera. Esta última -de interés en la presente colaboración- es entendida como, la capacidad del municipio para contar con recursos suficientes derivados de renglones tributarios exclusivos, así como el libre manejo de su patrimonio y la libre disposición de su hacienda. ${ }^{4}$

El diseño y disposiciones constitucionales, legales y administrativas que en materia económica se han implementado en el ámbito municipal formalmente han tenido como propósito, consolidar la autonomía municipal; así como el cumplimiento eficaz y eficiente de las atribuciones encomendadas. Desde la discusión del constituyente originario en $1917^{5}$ se ha tenido claro que sin suficiencia presupuestal -autonomía económica- no podría, ni podrá existir autonomía política; y en nuestros días es algo que se observa con claridad meridiana por el deficiente desempeño y crisis económicas que padecen dichos gobiernos locales. La descentralización de nuevas atribuciones normativas, así como la transferencia de recursos federales, en mucho casos han generado problemas, más que soluciones. Los municipios no han correspondido con la capacidad institucional ${ }^{6}$ requeridadeseada.

${ }^{3}$ Sobre el particular véase: Rendón Huerta Barrera, T.: Derecho municipal, 4. ${ }^{\text {a }}$ edición corregida y actualizada, Porrúa, México, 2007, pp. 125-138. QUINTANA RoLDÁN, C. F.: Derecho municipal, 9. ${ }^{a}$ edición revisada y actualizada, Porrúa, México, 2008, pp. 175-201. Valencia Carmona, S.: Derecho municipal, 2. edición, Porrúa - UNAM, México, 2006, pp. 174-175.

${ }^{4}$ Quintana Roldán, Ob. cit., p. 195.

5 En una de las discusiones para la aprobación de la fracción II del artículo 115 constitucional, relativa a la autonomía financiera, el diputado HERIBERTO JARA, uno de los defensores de dicha autonomía sostuvo que el municipio solo lograría su libertad, cuando éste gozara de libertad económica, con ésta se aseguraban todas las libertades. En otra de las discusiones expuso que,... si damos por un lado la libertad política, si alardeamos de que los ha amparado una revolución social y que bajo este amparo se ha conseguido una libertad de tanta importancia y se ha vuelto al municipio lo que por tantos años se le habia arrebatado, seamos consecuentes con nuestras ideas, no demos libertad por una parte y restrinjamos por la otra; no demos libertad politica y restrinjamos hasta lo último la libertad económica, porque entonces la primera no podrá ser efectiva.... Véase en: Los derechos del Pueblo Mexicano, tomo VIII, p. 309.

${ }^{6}$ No existe uniformidad en el término-capacidad institucional, capacidad estatal, capacidad de gestión pública o capacidad administrativa-, al igual que en los elementos o aspectos que la integran; o los tipos de aproximaciones de ésta; no obstante lo anterior 
En la perspectiva referida, la presente colaboración tiene como propósito presentar un esquema genérico de la situación económica, financiera y tributaria de los municipios mexicanos. Lo anterior, a efecto de dibujar -algunaspropuestas de corte normativo y administrativo que contribuyan a un mejor escenario financiero y económico de dichos entes de gobierno.

\section{DISPOSICIONES CONSTITUCIONALES EN MATERIA ECONÓMICA, FINANCIERA Y TRIBUTARIA PARA EL MUNICIPIO MEXICANO}

Para el debido cumplimiento de los servicios públicos y funciones referidas se otorga a dichos gobiernos locales la atribución de manejar su patrimonio (fracción II-115 CPEUM) bajo los parámetros que dispongan las legislaturas respectivas. Es la fracción IV del numeral referido (CPEUM) la que establece los diversos principios y facultades en materia económica, ${ }^{7}$ financiera $^{8}$ y tributaria ${ }^{9}$ a cargo de los municipios al establecer que estos adminis-

en términos generales se refiere, a la habilidad de las organizaciones para absorber responsabilidades, operar más eficientemente y fortalecer la rendición de cuentas. Esta capacidad se construye fortaleciendo a la organización a partir de su diversidad, pluralismo, autonomía e interdependencia con relación a otras organizaciones en el sistema. En este sentido, construir capacidad institucional significa también promover y crear redes de interacción entre las organizaciones del sector público y privado y las organizaciones no gubernamentales. Véase en ROSAS HUERTA, A.: «Una ruta metodológica para evaluar la capacidad institucional» en Politica y Cultura, núm. 30, 2008, Universidad Autónoma Metropolitana Unidad Xochimilco, Distrito Federal, México, p. 123. O en términos de CARRERA, como la habilidad o suficiencia de la configuración de las Instituciones del sector público para permitir la coordinación y la agregación de intereses divergentes a fin de promover políticas que reflejen el interés público y garanticen la prestación eficiente de servicios. Y para una perspectiva interior, las capacidades institucionales se refieren a los mecanismo de gestión de recursos humanos (reclutamiento, entrenamiento, promoción, evaluación), materiales y financieros (control de gestión, rendición de cuentas, transparencia). Desde una óptica externa denota capacidad que tienen las unidades administrativas para asesorar e implementar políticas, relacionándose así con otros actores públicos y privados. Véase en: CARRERA HERNÁNDEZ ADY, P. et al.: Índice de desarrollo institucional y sustentabilidad municipal, Red de Investigadores en Gobiernos Locales Mexicanos, A.C., México, 2010.

7 Relacionada con la incorporación, consolidación y disposición de los bienes y servicios que integran el patrimonio del municipio (solvencia) a partir de las fuentes constitucional y legalmente establecidas.

${ }_{8}$ Relacionada con los criterios que se adoptan para disponer de los recursos que el municipio tiene a su disposición (liquidez).

9 Entendiendo por ésta a la facultad que posee el municipio para establecer, previo procedimiento establecido en la fracción que nos ocupa, los tributos necesarios para solventar los servicios y funciones públicas que constitucionalmente le son asignadas. 
trarán libremente su hacienda $;^{10}$ la cual se integra con recursos de origen propio establecidos en las leyes que las Legislaturas Locales expiden para tales efectos; y por participaciones presupuestales provenientes de la Federación, por virtud del Sistema Nacional de Coordinación Fiscal. En tenor de lo anterior tenemos que,

I. Los ingresos propios son determinados en las Leyes de Ingreso correspondientes aprobadas por las Legislaturas Locales, y se clasifican en:

a) Impuestos. Son las prestaciones establecidas en ley que deben pagar las personas físicas o morales que se encuentren en la situación jurídica o de hecho prevista por la misma; tales como el predial; sobre conjuntos urbanos; sobre anuncios publicitarios; sobre diversiones, juegos y espectáculos públicos; sobre adquisición de inmuebles y otras operaciones traslativas de dominio de inmuebles; entre otras. El Impuesto predial es uno de los más importantes que posee el municipio, éste se calcula ${ }^{11}$ a partir del tamaño de los pre-

${ }^{10} \mathrm{El}$ término tiene su origen en el verbo latino facere, con el adjetivo pública hace referencia al conjunto de ingresos, propiedades y gastos de los entes públicos y constituye un factor de gran importancia en el volumen de la renta nacional y su distribución entre los grupos sociales. Véase: Diccionario Jurídico Mexicano, T. IV, E - H, Serie Varios, No. 25, Instituto de Investigaciones Jurídicas - UNAM, México - UNAM, 1983, p. 319. Para el caso de la hacienda pública municipal como lo hemos referido se integra de los rendimientos de sus bienes; las contribuciones que le sean determinados por la Legislatura Local respectiva; las participaciones federales; otros ingresos que perciban; así como las erogaciones que realicen; y en un contexto dinámico comprende cuatro funciones: ingresos; egresos; deuda pública; y, patrimonio, mismos que constituyen los elementos esenciales de la actividad financiera pública.

${ }^{11}$ Para calcular el valor del suelo, el primer criterio que se utiliza es la ubicación del inmueble. De acuerdo con su ubicación, existen tres tipos de valor de suelo, área de valor. Esto implica un cálculo con base en un grupo de manzanas (grupo de casas ubicadas en el mismo lote o área) que tienen características parecidas en cuanto a infraestructura y equipamiento urbano (servicios), tipo de inmuebles (casas unifamiliares, condominios, locales comerciales, fábricas, etcétera) y dinámica inmobiliaria. Enclave de valor. El cálculo por enclave se hace cuando una porción de manzanas o lotes habitacionales son notoriamente diferentes en valor y características, con respecto a los demás en un área específica; y finalmente corredor de valor. Es el cálculo que se hace cuando el inmueble se encuentra en una avenida o vialidad importante o muy transitada. Este cálculo se hace en función de que las grandes vialidades aumentan el valor comercial de una propiedad al incrementar la actividad económica de la zona. Este cálculo se aplica aun cuando el inmueble no tenga su acceso principal sobre la vialidad en cuestión. Después de realizar el cálculo del valor del suelo, se computa el avalúo de la construcción, para esto, se toman en cuenta factores como, tipo de inmueble (habitacional o comercial); número de pisos (tanto de la construcción general, como del propio inmueble), por ejemplo, puede tratarse de un departamento de dos niveles, que se encuentra dentro de un edificio de diez pisos); 
dios y el avalúo de sus construcciones, cuestión que implica la existencia y administración competente de una base de datos cartográfica actualizada de los predios con una cobertura completa en el territorio municipal. ${ }^{12}$

b) Derechos. Son las prestaciones establecidas en ley por percibir servicios que prestan las dependencias y entidades de la Administración Pública Municipal, en sus funciones de derecho público; así como por el uso o disfrute de los bienes del dominio público del municipio; así como las actividades de los particulares sujetas a control municipal con motivo de la explotación de un bien público. Entre estos encontramos, por ejemplo, el agua potable, drenaje, alcantarillado, tratamiento y disposición de aguas residuales; del registro civil; del desarrollo urbano y obras públicas; por servicios de rastro; por servicios de panteones; por servicio de alumbrado público; por servicios prestados por las autoridades de catastro; entre otras;

c) Contribuciones por mejoras. Son las prestaciones a cargo de las personas físicas o morales que, con independencia de la utilidad general, obtengan un beneficio diferencial particular derivado de la realización de obras públicas; por ejemplo, introducción, ampliación y rehabilitación de sistemas de agua potable y drenaje; construcción, ampliación y rehabilitación de sistemas para el saneamiento del agua; urbanizaciones tales como guarniciones, aceras, pavimentación, repavimentación o mantenimiento de calles, vialidades o caminos rurales; entre otros;

d) Productos. Son contraprestaciones por los servicios que preste el Municipio en sus funciones de derecho privado, así como por el

superficie del terreno; y superficie y antigüedad de la construcción. Por último, para realizar el cálculo, se toman en cuenta los rangos de valores. Esto quiere decir que existen tablas que marcan el monto del impuesto predial de acuerdo con el rango de valor catastral en que se encuentra una vivienda. El rango se presenta tomando en cuenta el límite inferior y el límite superior de precio. Esto quiere decir que, si el rango uno fuera, por ejemplo, de viviendas entre un peso y cien mil pesos y yo tengo una vivienda con valor catastral de cincuenta mil pesos y mi vecino tiene una con valor de treinta mil pesos, ambos seremos acreedores a la misma cuota única. Así pues, los resultados del cálculo no sólo dependen del número de metros cuadrados del inmueble, sino también de la zona y tipo de construcción, condiciones topográficas, equipamiento y servicios urbanos con que cuenten. Recuperado en: https://finanzaspracticas.com.mx/finanzas-personales/etapas-dela-vida/alquiler-o-compra-de-vivienda/el-pago-de-impuesto-predial?print=y

12 Robinson, S. S.: Participación ciudadana en la hacienda municipal: paradojas para la antropología politica, recuperado en: http://www.inafed.gob.mx/work/ siha_2015/5/Participacion_ciudadana_en_la_hacienda_municipal.pdf 
uso, aprovechamiento o enajenación de sus bienes de dominio privado. Al igual que los ingresos provenientes de la venta de primera mano que, por la explotación de sus bienes de dominio privado, haga el Ayuntamiento al realizar actividades agrícolas, ganaderas, pesqueras, agrícolas, ganaderas, pesqueras, silvícolas o cualesquiera otras de naturaleza similar. En otros términos, son los ingresos por actividades que no corresponden al desarrollo de las funciones propias del municipio; sino que se generan por el uso o aprovechamiento de sus bienes patrimoniales, esto es, los derivados de la venta o arrendamiento de bienes municipales; utilidades, dividendos y rendimientos de inversiones en créditos, valore y bonos, por acciones y participaciones en sociedades o empresas; rendimientos o ingresos derivados de las actividades de organismos descentralizados y empresas de participación municipal, cuando por su naturaleza correspondan a actividades que no son propias de derecho público; impresos y papel especial; entre otros; $y$,

e) Aprovechamientos. Son ingresos que percibe el municipio en sus funciones de derecho público distintos de las contribuciones, de los ingresos derivados de financiamientos y de los que obtengan los organismos descentralizados y las empresas de participación estatal; tales como reintegros; uso o explotación de bienes de dominio público; sanciones administrativas; indemnizaciones por daños a bienes municipales; subsidios, subvenciones, donativos, herencias, legados y cesiones.

II. Respecto a las participaciones presupuestales provenientes de la Federación. Estas son fondos constituidos en beneficio de Estados y municipios, con cargo a recursos que la Federación transfiere al Estado, como consecuencia de su adhesión al Sistema Nacional de Coordinación Fiscal. ${ }^{13}$

En este rubro encontramos las denominadas aportaciones; $y$ las participaciones, las primeras son recursos que la Federación transfiere a las haciendas públicas municipales con un carácter distributivo y compensatorio dirigida al desarrollo a las cuales se les condiciona su gasto a la consecución y cumplimento de los objetivos establecidos en la Ley de Coordinación Fiscal (LCF).

Las participaciones por su parte, tienen un componente resarcitorio, ya que tienen como propósito compensar la pérdida de las Entidades Federati-

${ }^{13}$ Mediante el cual, de conformidad con el artículo $1 .^{\circ}$ de la Ley de Coordinación Fiscal, se establece la participación que corresponde a las haciendas públicas de los Estados miembros y municipios, en los ingresos federales. 
vas por la renuncia de su potestad tributaria originaria de determinadas fuentes de ingresos, cuya tributación queda a cargo de la Federación.

Para el ámbito municipal los dos fondos más importantes de transferencias económicas son, el de Fondo de Aportaciones para Infraestructura Social (FAIS) $;{ }^{14}$ y el Fondo de Aportaciones para el Fortalecimiento de los Municipios y de las Demarcaciones Territoriales del Distrito Federal (FORTAMUNDF). ${ }^{15}$

Bajo la composición o integración hacendaria referida, y de conformidad a la fracción IV-115 (CPEUM); y tesis ${ }^{16}$ dictada por el Poder Judicial de la Federación, la hacienda municipal es regida por algunos principios, en primer término, por el principio de libre administración de la hacienda municipal, el cual tiene como propósito fortalecer la autonomía y autosuficiencia económica de los gobiernos locales; que sean éstos los que decidan de manera libre sobre la aplicación de sus recursos para satisfacer las necesidades que ellos consideren apremiantes, y satisfagan sus necesidades sin estar afectados por intereses ajenos que los direccionen u obliguen a ejercer en rubros no prioritarios o distintos al de sus necesidades reales. La excepción a este principio la encontramos en las aportaciones federales, como lo hemos referido y de conformidad con la LCF, tienen un efecto redistributivo que pretenden el desarrollo de los estados y municipios con mayor debilidad económica, por lo tanto se etiquetan para que no pueden destinarse a otro tipo de gasto más que el indicado por los fondos correspondientes establecidos en la Ley mencionada.

El segundo principio es el relativo al ejercicio directo del ayuntamiento de los recursos que integran la hacienda pública municipal, el cual implica que todos los recursos de la hacienda municipal, incluso los que no están sujetos al régimen de libre administración hacendaria -como las aportaciones federales-, deben ejercerse en forma directa por los ayuntamientos o por quienes ellos autoricen conforme a la ley. Así, aun en el caso de las aportaciones federales esta garantía tiene aplicación, ya que si bien estos recursos están preetiquetados, se trata, únicamente, de una preetiquetación temática en la que los gobiernos municipales tienen la posibilidad de decidir en qué obras o actos invertirán los fondos, bajo las premisas de atender las necesida-

${ }^{14}$ Dicho fondo se distribuye con criterios compensatorios, en función del porcentaje de pobreza que los municipios aportan a sus respectivas entidades federativas.

${ }^{15}$ Este se distribuye con criterios distributivos, en función del porcentaje que representa la población del municipio respecto al total estatal.

${ }^{16}$ Controversia constitucional 70/2009. Municipio de Santiago Yaveo, Choapam, Estado de Oaxaca. 2 de junio de 2010. Cinco votos. Ponente: José Ramón Cossío Díaz. Secretarios: Laura Patricia Rojas Zamudio y Raúl Manuel Mejía Garza. Época: Novena Época. Registro: 163468 Instancia: Primera Sala. Fuente: Semanario Judicial de la Federación y su Gaceta, Tomo XXXII, Noviembre de 2010, Materia(s): Constitucional, Tesis: 1a. CXI/2010, Pág. 1213 
des; y, a posteri, rendir cuentas de su utilización en la revisión de la cuenta pública correspondiente. ${ }^{17}$ Así como el principio de reserva de fuentes de ingresos municipales, que asegura a los municipios tener disponibles ciertas fuentes de ingreso para atender el cumplimiento de sus necesidades y responsabilidades públicas. ${ }^{18}$

De conformidad con lo establecido en el artículo 6 de la LCF se deriva el principio de integridad de los recursos municipales, consistente en que los municipios por conducto de los Estados dentro de los cinco días siguientes a aquel en que el Estado las reciba, tienen derecho a la recepción puntual, efectiva y completa tanto de las participaciones como de las aportaciones federales, pues en caso de entregarse extemporáneamente, se generará el pago de los intereses correspondientes;

Finalmente, una disposición importante en la fracción que nos ocupa es la posibilidad que los ayuntamientos poseen para que en el ámbito de sus respectivas competencias propongan a las legislaturas estatales las cuotas y tarifas aplicables a impuestos; derechos; contribuciones de mejoras; $y$, las tablas de valores unitarios de suelo y construcciones que sirvan de base para el cobro-percepción de las contribuciones sobre la propiedad inmobiliaria, entre otros. En dicho contexto, y en estricta legalidad los municipios carecen de facultad tributaria absoluta al ser las Legislaturas Locales las que determinan y aprueban las contribuciones que los habitantes deben cubrir a la hacienda municipal; el procedimientos legislativo fiscal municipal es una potestad tributaria compartida, toda vez que la facultad para determinar contribuciones, originalmente se encuentra reservada al órgano legislativo (artículo 31, fracción IV de la CPEUM) misma que es complementada con los principios de reserva de fuentes, así como con la norma expresa que otorga al municipio la facultad de iniciativa, por lo que aún cuando la decisión final corresponde a la legislatura, ésta se encuentra condicionada por la Norma Fundamental a dar el peso suficiente a dicha iniciativa, lo cual se concreta en la motivación que tendrá que sustentar en caso de que se aparte de ésta. ${ }^{19}$

17 Ídem.

18 Ídem.

19 HACIENDA MUNICIPAL. EN EL CASO DE LOS TRIBUTOS A QUE SE REFIERE LA FRACCIÓN IV DEL ARTÍCULO 115 DE LA CONSTITUCIÓN POLÍTICA DE LOS ESTADOS UNIDOS MEXICANOS, EXISTE UNA POTESTAD TRIBUTARIA COMPARTIDA ENTRE LOS MUNICIPIOS Y EL ESTADO EN EL PROCESO DE SU FIJACIÓN. Controversia constitucional 15/2006. Municipio de Morelia, Estado de Michoacán de Ocampo. 26 de junio de 2006. Unanimidad de diez votos. Ausente: Margarita Beatriz Luna Ramos. Ponente: Genaro David Góngora Pimentel. Secretarios: Makawi Staines Díaz y Marat Paredes Montiel. Época: Novena Época. Fuente: Semanario Judicial de la Federación y su Gaceta. Tomo XXIV, Octubre de 2006. Materia(s): Constitucional. Tesis: P./J. 111/2006, pág. 1129 


\section{CONTEXTO ACTUAL. ASPECTOS ECONÓMICOS, FINANCIEROS Y TRIBUTARIOS}

Con base en las disposiciones constitucionales y legales en materia económica para que los municipios mexicanos enfrenten el cúmulo de atribuciones que les corresponde atender, a priori, podríamos afirmar que sus fuentes de ingresos, así como el incremento de recursos económicos que vía transferencias federales se les han otorgado ${ }^{20}$ (gráfica 1 ) serían suficientes para enfrentar sus necesidades, no obstante, la realidad se encuentre distante a tal afirmación.

\section{Gráfica 1. Evolución de la Aportaciones Federales a los Municipios (Ramo 033)}

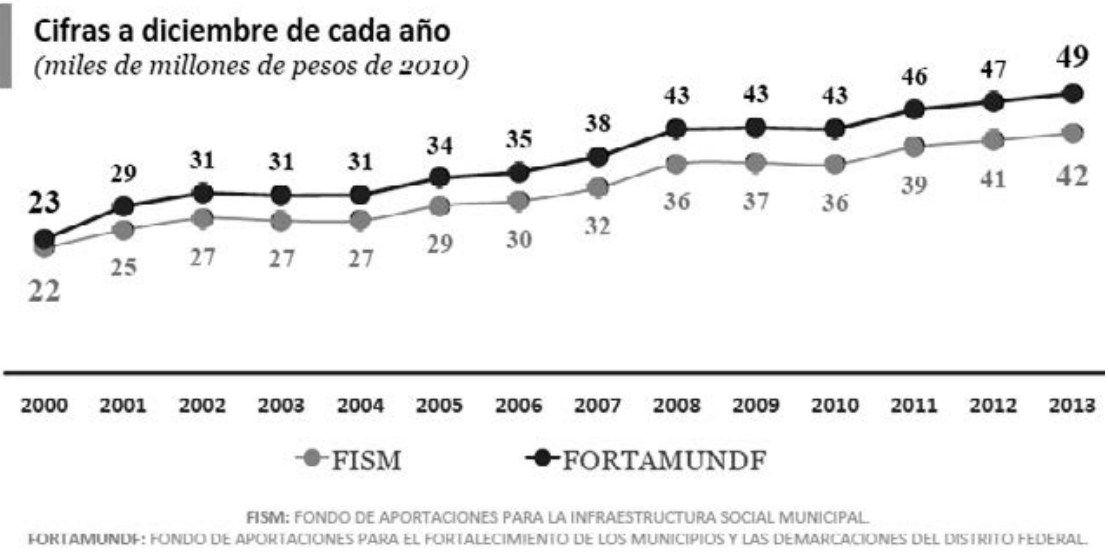

Tomada del Índice de Información Presupuestal Municipal 2014.

Elaborado por el Instituto Mexicano para la Competitividad, A. C. - IMCO ${ }^{21}$.

Diversas son las problemáticas que en materia económica, financiera y tributaria enfrentan los municipios. Una de estas es el efecto negativo que las transferencias federales han generado en los gobiernos locales; estudios ${ }^{22}$

${ }^{20}$ De acuerdo al Presupuesto de Egresos de la Federación para el Ejercicio Fiscal 2015 se aprobaron $\$ 110,448,558,487$ millones de pesos, de los cuales, \$51,306 millones de pesos corresponden a FISM; y \$59,142 millones de pesos a FORTAMUNDF.

${ }^{21}$ Recuperado en: http://imco.org.mx/indices/indice-de-informacion-presupuestalmunicipal-2014/

22 Véanse Hernández Trillo, F. y Iturribarría, H.: Tres trampas del federalismo fiscal mexicano, Cuadernos de trabajo, n² 281, CIDE, México, Octubre 2003. DíAz CA- 
concuerdan que dichas transferencias no solo han desincentivado el esfuerzo fiscal de los gobiernos municipales (gráfica 2); sino que además, el efecto de los recursos no se han visto reflejados en el desarrollo regional.

\section{Gráfica 2. Evolución de las transferencias federales e ingresos propios de las entidades federativas y municipios ${ }^{23}$}

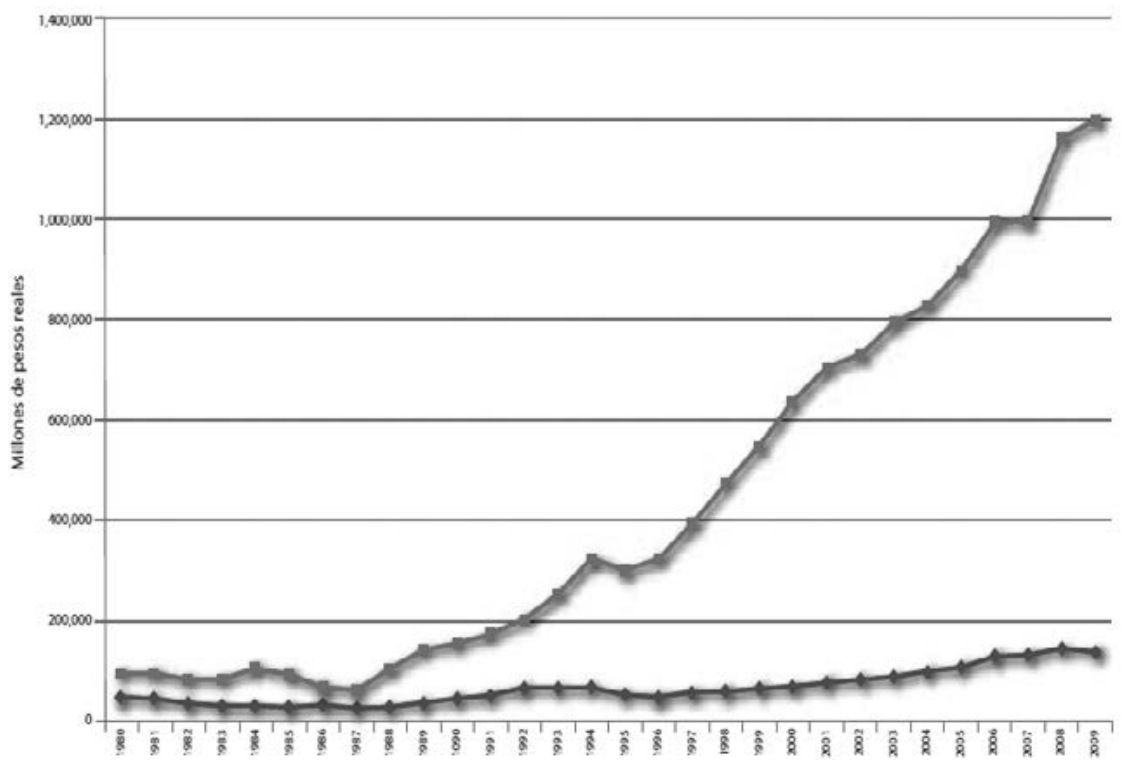

En dicha perspectiva estudio del Instituto Nacional para el Federalismo y el Desarrollo Municipal24 (INAFED) sostiene que, en 1999 el $22.4 \%$ del

YERO, A.: «El federalismo y los límites políticos de la redistribución», en Gestión y Politica Pública, vol. XIII, No. 3, II semestre 2004, CIDE, México. CABrero MendozA, E.: «La trampa del federalismo fiscal» en Nexos, noviembre 2008 recuperado en http://www. nexos.com.mx/?p=12811

23 Tomada de: Peña Ahumada, J. A. y Armando Wence Partida, L.: «La distribución de transferencias federales para municipios, ¿qué incentivos se desprenden para el fortalecimiento de sus haciendas públicas?», en Hacienda Municipal. Revista trimestral, 4-2011, Sistema de Nacional de Coordinación Fiscal, No. 115, Octubre - diciembre 2011, INDETEC.

24 Peña Ahumada, J. A. y Bojórquez Carrillo, A. L.: Autonomía financiera municipal, Serie Coloquio sobre Federalismo, No. 2, Instituto Nacional para el Federalismo y el Desarrollo Municipal - SEGOB, México, 2012, p. 2. 
gasto total de los municipios era recaudado directamente por ellos, en 2010 dicha recaudación disminuyó al 20.8 \%; que en 1999 los gobiernos locales costeaban casi el $80 \%$ de su gasto de nómina con recursos de fuente propia, para 2010 lograron cubrir apenas el $66 \%$; de igual forma, en 1999 dichos gobiernos locales en 1999 cubrían con ingresos propios el $46.5 \%$ de su gasto de operación, en tanto, para 2010 solo cubrieron el $43.5 \% .{ }^{25}$ Por lo que respecta al crecimiento económico de éstos es raquítico, generan el $2.9 \%$ de los ingresos totales del País (PIB), y consumen el $8.3 \%$ de tales ingresos totales, esto es, gastan casi tres veces más de lo que logran aportar, de tal suerte que sus ingresos se integran de la siguiente manera:

\section{Gráfica 3. Integración de los ingresos municipales}
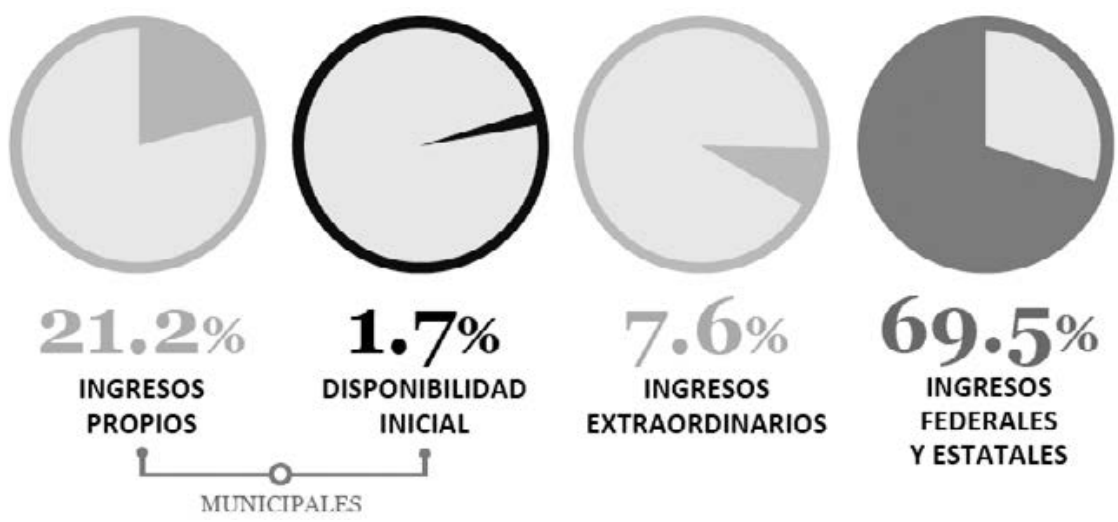

Tomada del Índice de Información Presupuestal Municipal 2014.

Elaborado por el Instituto Mexicano para la Competitividad, A. C. - IMCO ${ }^{26}$.

Ante tal contexto, resulta incomprensible que una importante fuente recaudatoria, como lo es el impuesto predial no sea agotada y en México los ingresos por dicho impuesto apenas represente el $0.13 \%$ del PIB del País, en tanto que en Países como Chile o Uruguay representen el $0.60 \%$ y $0.65 \%$ respectivamente, ${ }^{27}$ en tal sentido la OCDE sostiene que, los ingresos por el impuesto predial son excepcionalmente bajos incluso en comparación con sus homólogos latinoamericanos... Lo mismo sucede con el agua, que es del

25 Ídem.

${ }^{26}$ Recuperado en: http://imco.org.mx/indices/indice-de-informacion-presupuestalmunicipal-2014/

${ }^{27}$ OCDE, Tax Revenue Database y Latin American Revenue Statistics. 
ámbito municipal y que presenta una enorme variedad en las tarifas, desde algunos casos en los que no se cobra hasta algunos casos que, lamentablemente son la excepción, en los cuales se cubren los costos. ${ }^{28}$

Ahora bien, la dependencia de transferencias federales y la nula capacidad de recaudación no son las únicas situaciones complejas que enfrenta el municipio mexicano, adolece además de un grave endeudamiento; para junio de 2014 el saldo de la deuda municipal ascendía a la cantidad de \$54,670.4 millones de pesos, ${ }^{29}$ la cual en siete años tuvo un incremento del $89 \%$ (ver gráfica 4 ).

\section{Gráfica 4. Cronología de la deuda municipal en México}

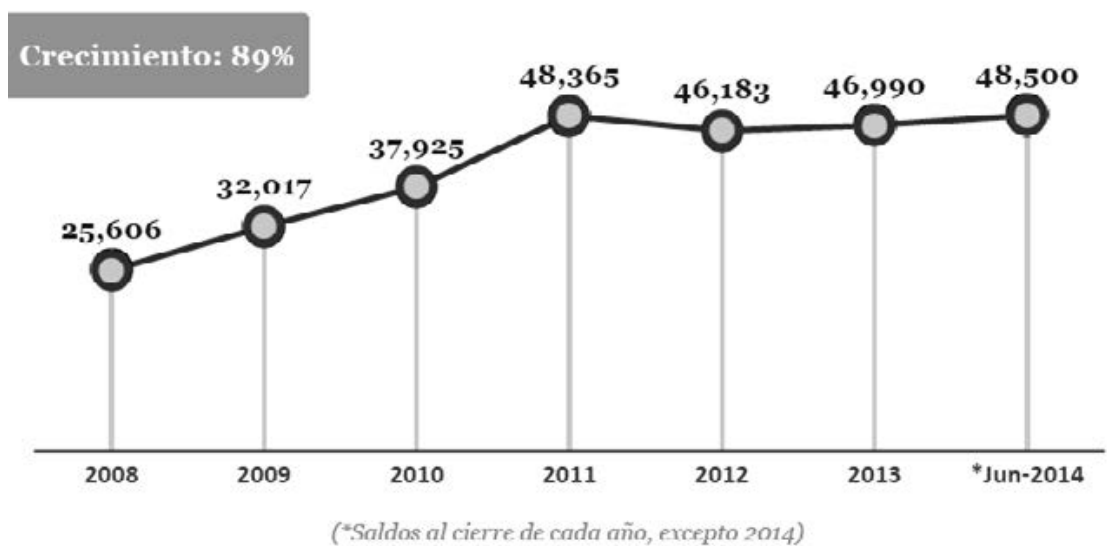

Tomada del Índice de Información Presupuestal Municipal 2014 - Instituto Mexicano para la Competitividad - $\mathrm{IMCO}^{30}$.

Según datos de la Secretaría de Hacienda y Crédito Público (SHCP) el endeudamiento no solo ha sido de los municipios, sino también de las entidades federativas, la deuda de ambos niveles de gobierno asciende al $3.1 \%$ del PIB, misma que entre los años 2008 y 2013 tuvo un crecimiento acelerado al pasar del $1.7 \%$ al $3.1 \%$ del PIB. ${ }^{31}$

${ }^{28}$ OCDE, México. Mejores politicas para un desarrollo incluyente, Serie «Mejores políticas», México, septiembre 2012, p. 16.

29 Índice de Información Presupuestal Municipal 2014 - Instituto Mexicano para la Competitividad - IMCO. Recuperado en http://imco.org.mx/indices/indice-de-informacion-presupuestal-municipal-2014/

30 Ídem.

${ }^{31}$ Una respuesta a tal situación es la Ley de Disciplina Financiera de las Entidades Federativas y los Municipios misma que se encuentra en proceso legislativo (aprobación 


\section{ALGUNAS RUTAS PARA LA SOLUCIÓN}

Fortalecer la autonomía financiera municipal implica atender el problema desde diversos aspectos, toda vez que son diferentes los factores que inciden en la debilidad, o incluso, ausencia de autonomía en la vertiente en cuestión.

Con base en diversos estudios en el rubro, así como algunas reflexiones de nuestra parte, estimamos que la solución a los problemas referidos invariablemente debe transitar: por el diseño de un nuevo federalismo fiscal que incentive la recaudación local; el ejercicio pleno de la facultad reglamentaria municipal; alentar y fortalecer la capacidad institucional; transparencia y fácil acceso a la información como instrumentos de rendición de cuentas; y estricta vigilancia en la aplicación de los recursos por parte de los entes fiscalizadores, acompañada ésta de cero tolerancia a la impunidad.

Un nuevo federalismo fiscal. Se afirma que, el diseño actual de las formulas estatales de distribución de las transferencias federales que reciben los municipios no es el adecuado ${ }^{32}$ según lo establecido en los postulados teóricos de la descentralización fiscal, así como otros puntos de referencia de tipo internacional; amén de carecer de una asignación óptima de tareas fiscales entre los diferentes órdenes de gobierno, tanto en lo relativo a la recaudación, como en el ejercicio del gasto público. ${ }^{33}$ Se refiere que si bien es cierto que las transferencias federales (FAISM - FORTAMUNDF) dado los fines compensatorio - nivelador, no tienen como objetivo el incentivar alguna conducta en aspectos financieros y de desarrollo municipal, el diseño de

del Constituyente Permanente), y la cual tiene como propósito asegurar el manejo sostenible de las finanzas públicas de las entidades federativas, el Distrito Federal y los gobiernos municipales. Por ello propone principios generales en materia presupuestaria, de endeudamiento, transparencia, monitoreo y rendición de cuentas del uso de los ingresos y del ejercicio del gasto público de las entidades federativas y de los municipios. Cinco son sus aspectos principales: Uno, reglas de Disciplina Financiera, que promuevan el sano desarrollo de las finanzas públicas, mediante principios de responsabilidad hacendaria; dos, Sistema de Alertas, vinculado a los niveles.de endeudamiento, de servicio de la deuda y de las condiciones de liquidez, que permita una detección oportuna del riesgo en el endeudamiento de los entes públicos; tres, contratación de financiamientos y obligaciones, bajo 1 os de transparencia y eficiencia, de forma que su contratación se realice al menor costo financiero y destinando los recursos obtenidos a inversión pública; cuatro, deuda estatal garantizada, a través de la cual la Federación, de acuerdo a la autorización constitucional, otorgará su aval con el único objetivo de apoyar a los estados y los municipios para reducir la tasa de interés de sus créditos. Lo anterior, a cambio de generar convenios de disciplina financiera; y, cinco, la creación de un Registro Público Único, para inscribir y transparentar la totalidad de las obligaciones de los gobiernos locales. Recuperado en: http://www.indetec.gob.mx/2015/wp-content/uploads/e-Financiero/296/ Noticias/BoletinNo296_4.pdf

32 Peña Ahumada, J. A. y Armando Wence Partida, L.: ob. cit., p. 80.

33 Ibídem, p. 81. 
sus fórmulas puede tener efectos no deseados tanto en la propia función de abatir el rezago regional, como en el simple hecho de no ofrecer ningún incentivo capitalizable para incrementar los ingresos propios y mejorar la calidad del gasto municipal (el tamaño poblacional no es una variable que pueda controlarse para dicho fin en lo que respecta al FORTAMUNDF). ${ }^{34}$

Los autores concluyen, ${ }^{35}$ siguiendo a Hernández e Iturribarría, que la entrega de transferencias de tipo niveladoras o compensatorias a los gobiernos municipales deben ser complementadas con transferencias resarcitorias, para evitar desincentivar la recaudación y nivelar, única y exclusivamente, la menor generación de recursos propios, derivado del hecho de que tienen bases gravables menores, pero no porque realizan un menor esfuerzo fiscal. Toda vez que en las entregas que hacen las entidades federativas a los municipios no existe claridad en los incentivos de las participaciones que favorezcan la recaudación local; existen variados criterios de asignación para dichas transferencias, muchos de los cuales no están alineados al sentido de la reforma en la legislación federal. ${ }^{36}$

Ejercicio pleno de la facultad reglamentaria municipal. Como lo hemos referido, los municipios poseen la facultad materialmente legislativa, aunque formalmente reglamentaria, mediante la cual, $\mathrm{y}$, en concordancia con las leyes que en el ámbito municipal expidan las legislaturas de los estados pueden contar con sus Bandos de Policía y Buen Gobierno, así como con los reglamentos necesarios ${ }^{37}$ para un eficaz y eficiente desempeño administrativo. No obstante lo anterior, lo que encontramos en la realidad es obsolecencia o debilidad normativa; ${ }^{38} \mathrm{o}$, en otros casos, ausencia del marco reglamentario municipal tal como se puede corroborar en el Índice de Reglamentación Municipal Básica 2012 elaborada por el INAFED con base en el Censo Nacional de Gobiernos Municipales y Delegacionales 2013 realizado por el INEGI. ${ }^{39}$

Una de las consecuencias por la ausencia de la reglamentación municipal, es que los Ayuntamientos dejan de percibir importantes cantidades de recursos económicos, vía imposición de sanciones jurídicamente permitidas.

34 Ibidem, p. 91.

35 Ibidem, p. 95.

36 Ídem.

37 Comercio, Industria y Espectáculos; Protección Animal; Protección Civil; Protección Ambiental y Desarrollo Sostenible; De Servicios Públicos Municipales; De Seguridad Pública; Vialidad y Tránsito; De Participación Ciudadana; Protección animal; Regulación Interna; y De Transparencia y Acceso a la Información, entre otros

${ }^{38}$ Es importante precisar que la existencia normativa referida no implica actualización y apego a los cambios jurídicos de largo alcance que se han generado a partir de junio de 2011.

39 Puede consultarse en: http://www.inafed.gob.mx/es/inafed/Desempeno_Institucional_Municipal 
Alentar y fortalecer la capacidad institucional: Hemos referido en líneas anteriores que entendemos por capacidad institucional, a la habilidad de las organizaciones para absorber responsabilidades, operar más eficientemente y fortalecer la rendición de cuentas. Esta capacidad se construye fortaleciendo a la organización a partir de su diversidad, pluralismo, autonomía e interdependencia con relación a otras organizaciones en el siste$m a .^{40} \mathrm{Y}$ que en dicho contexto poseer capacidad institucional también impli$\mathrm{ca}$, promover y crear redes de interacción entre las organizaciones del sector público y privado y las organizaciones no gubernamentales. ${ }^{41}$

No obstante lo anterior, la relación-aproximación a la cuestión administrativa, no es la única, Rosas Huerta bajo el esquema de Nelissen sugiere otros tres tipos de aproximaciones, la jurídica, la económica; y, la política-social. ${ }^{42}$ Para efectos del presente trabajo solo haremos referencia a dos elementos de la capacidad administrativa de los municipios, toda vez que elementos de las aproximaciones jurídica y política-social, las hemos considerado como variables independientes en el presente apartado. En tenor de lo anterior, únicamente haremos referencia a aspectos específicos de recursos humano y material del municipio; toda vez que en la evaluación de la capacidad administrativa un aspecto fundamental es el nivel de conocimientos, capacitación, y experiencia de su personal, de sus funcionarios, así como los recursos materiales que se poseen.

La ausencia de capacitación técnica y administrativa al personal; la ausencia de un servicio civil de carrera municipal; así como el recurrente cambio de personal -de confianza- por la renovación de los períodos de gobiernos, se ha convertido en un círculo vicioso que genera un desempeño deficiente de los funcionarios correspondientes; desperdicio de recursos económicos; e ineficaz e ineficiente desempeño institucional. ${ }^{43}$ Personal im-

40 Rosas Huerta, Ob. cit., p. 123.

41 Ídem.

${ }^{42}$ Por ello explica que, cuando el gobierno opta por una aproximación jurídica, sus acciones se rigen principalmente por el hecho de que opera en el marco de una Constitución, en una democracia y bajo principios establecidos de legalidad, orden, protección de los derechos fundamentales y compromiso de gobernar con justicia. En tanto cuando el gobierno opta por una aproximación hacia lo económico y a los negocios, sus acciones se rigen por las demandas relacionadas con la ejecución efectiva de las tareas de gobierno. La aspiración es manejar el gobierno como una corporación y las acciones se enfocan a mejorar la productividad de sus organizaciones. Finalmente, cuando se elige por una aproximación político-social, sus acciones se rigen por los valores que estructuran la democracia, tales como la representación política, la rendición de cuentas, la distribución de autoridad, el monitoreo y control, la participación política y la legitimidad social. Véase en Rosas Huerta, Ob. cit., p. 124.

${ }^{43}$ Según lo refiere un estudio del INAFED la Encuesta Nacional Gobierno, Seguridad Pública y Justicia Municipal 2009 realizada por el INEGI registró que 22 \% de los muni- 
provisado - $\mathrm{O}$, ausencia de capacitación al mismo-, regularmente trae aparejada la ausencia de herramientas o equipo suficiente para realizar las funciones encomendadas; el ejemplo perfecto lo encontramos en la necesaria actualización del castro municipal, ${ }^{44}$ a efecto de que el gobierno municipal conozca los bienes inmuebles asentados en su territorio, registre los datos exactos relativos a sus características, determine su valor y conozca la situación jurídica de los mismos respecto a sus propietarios, todo esto dirigido $a$ la captación de recursos a través del cobro de diferentes impuestos a la propiedad inmobiliaria, como son el predial y el de traslación de dominio, entre otros. ${ }^{45}$

En la ausencia, o deficiencia de los elementos que nos ocupa y en particular el caso de la actualización del catastro municipal, esto representa, como lo hemos referido en líneas anteriores, la escasa recaudación por concepto de impuesto predial; sobre el particular la OCDE sostiene que, es posible elevar la recaudación en este rubro haciendo que los municipios participen en programas estatales para la actualización de registros catastrales, y elevando las tasas con un umbral de exención suficientemente alto, lo que permitiría lograr un esquema progresivo, lo cual es importante en un país con fuerte desigualdad. ${ }^{46}$

Transparencia y acceso a la información instrumentos de rendición de cuentas. Un medio eficaz para planear las acciones de gobierno, y en paralelo un antídoto contra la corrupción e impunidad es la transparencia, el fácil acceso a la información pública, y la consecuente rendición de cuentas.

Como lo refieren López Ayllón y Mauricio Merino, transparencia es una política deliberada del Estado para producir y emplear sistemáticamente información como un recurso estratégico, destinado a facilitar y dotar de

cipios reconoce que el problema financiero de dichos entes se relaciona con la capacitación de sus funcionarios públicos.

${ }^{44}$ Catastro, es el censo analítico de la propiedad inmobiliaria, que tiene el propósito de ubicar, describir y registrar las características físicas de cada bien inmueble con el fin de detectar sus particularidades intrínsecas que lo definen tanto material como especialmente. La administración pública del catastro, tiene por objeto detectar las características de los bienes inmuebles ubicados en el territorio del municipio, conocer quiénes son los propietarios de dichos bienes y registrar su situación jurídica-económica para fines tanto legales como impositivos. Véase en: http://www.inafed.gob.mx/work/models/inafed/Resource/335/1/images/guia21_la_administracion_del_catastro_municipal.pdf.

45 Ídem.

${ }^{46}$ OCDE, México. Mejores politicas para un desarrollo incluyente, Ob. cit., pp. 15, 16. El mismo informe destaca que, lo mismo sucede con el agua, que es del ámbito municipal y que presenta una enorme variedad en las tarifas, desde algunos casos en los que no se cobra hasta algunos casos que, lamentablemente son la excepción, en los cuales se cubren los costos. 
contenido a la participación de los ciudadanos en los asuntos públicos $;{ }^{47}$ en tal contexto, la transparencia requiere del acceso a la información pública, toda vez que la rendición de cuentas es imposible en un entorno de opacidad y de ocultamiento de la información del gobierno, por ello, transparencia y el acceso a la información son condiciones necesarias para el proceso de rendición de cuentas, la cual invariablemente debe ser entendida como el conjunto de instituciones, normas y procedimientos que tiene como propósito fortalecer la legalidad y el sentido democrática de las responsabilidades públicas $y$ sancionar (positiva o negativamente) a los actores que las asumen. ${ }^{48}$

Los elementos referidos como puede deducirse resultan herramientas indispensables y de uso permanente para mejorar el desempeño de los municipios. Cuestión que implica voluntad política por parte de las autoridades, y participación ciudadana activa y demandante para decidir sobre los temas de la agenda pública, en especial en el rubro de los recursos públicos, su planeación, destino, uso.

Estricta vigilancia en la aplicación de los recursos por parte de los entes fiscalizadores, acompañada ésta de cero tolerancia a la impunidad. La tarea fiscalizadora en México es una instancia a la que se le suministra cantidades importantes de recursos económicos, no obstante tal suministración, el desempeño de tales instancias no es el deseado. A menudo se refieren no solo casos de grave corrupción, sino además, de galopante impunidad.

Si bien es cierto que este es un aspecto sumamente complejo, el cual podría considerarse, incluso, como una practica cultural, también es cierto que no se debe dejar de insistir y señalar que en tanto exista simulación y tolerancia en conductas que bien encuadran en tipos penales tales como enriquecimiento ilícito, peculado, cohecho, entre otros, no solo no se recobrará la confianza ciudadana; sino que además, parte importante del erario público seguirá siendo destinado a satisfacer intereses particulares de los gobernantes, y hacer caso omiso al grave deterioro de la infraestructura urbana; de las vías de comunicación; de la nula satisfacción de derechos sociales; entre otros aspectos.

\section{FUENTES}

\section{Bibliografia}

CARRERA Hernández Ady, P. et al.: Índice de desarrollo institucional y sustentabilidad municipal, Red de Investigadores en Gobiernos Locales Mexicanos, A.C., México, 2010.

${ }^{47}$ La rendición de cuentas en México: Perspectivas y retos, recuperado en: http://biblio.juridicas.unam.mx/libros/6/2800/4.pdf.

48 Ídem. 
DíAz CAyero, A.: «El federalismo y los límites políticos de la redistribución», en Gestión y Política Pública, vol. XIII, No. 3, II semestre 2004, CIDE, México.

Hernández Trillo, F. y ITURRIBARRÍA, H.: Tres trampas del federalismo fiscal mexicano, Cuadernos de trabajo, No. 281, CIDE, México, Octubre 2003.

OCDE, México. Mejores politicas para un desarrollo incluyente, Serie «Mejores políticas», México, septiembre 2012, p. 16.

OCDE, Tax Revenue Database y Latin American Revenue Statistics.

Peña Ahumada, J. A. y Armando Wence Partida, L.: «La distribución de transferencias federales para municipios, ¿qué incentivos se desprenden para el fortalecimiento de sus haciendas públicas?», en Hacienda Municipal. Revista trimestral, 4-2011, Sistema de Nacional de Coordinación Fiscal, No. 115, Octubre - diciembre 2011, INDETEC.

Peña Ahumada, J. A. y Bojórquez Carrillo, A. L.: Autonomía financiera municipal, Serie Coloquio sobre Federalismo, No. 2, Instituto Nacional para el Federalismo y el Desarrollo Municipal - SEGOB, México, 2012.

Quintana RoldÁn, C. F.: Derecho municipal, 9. edición revisada y actualizada, Porrúa, México, 2008.

RENDÓn Huerta BARRera, T.: Derecho municipal, 4. ${ }^{a}$ edición corregida y actualizada, Porrúa, México, 2007.

Valencia Carmona, S.: Derecho municipal, 2. a edición, Porrúa - UNAM, México, 2006.

VV AA, Diccionario Jurídico Mexicano, T. IV, E - H, Serie Varios, No. 25, Instituto de Investigaciones Jurídicas - UNAM, México - UNAM, 1983.

\section{Internet}

Índice de Información Presupuestal Municipal 2014 - Instituto Mexicano para la Competitividad - IMCO. Recuperado en http://imco.org.mx/indices/indice-deinformacion-presupuestal-municipal-2014/

Cabrero Mendoza, E., «La trampa del federalismo fiscal» en Nexos, noviembre 2008 recuperado en http://www.nexos.com.mx/?p=12811

\section{Legislación}

Constitución Política de los Estados Unidos Mexicanos.

Ley de Coordinación Fiscal.

Ley de Presupuesto de Egresos de la Federación para el Ejercicio Fiscal 2015.

Semanario Judicial de la Federación y su Gaceta, Tomo XXXII, Noviembre de 2010, Materia(s): Constitucional, Tesis: 1a. CXI/2010.

Semanario Judicial de la Federación y su Gaceta. Tomo XXIV, Octubre de 2006. Materia(s): Constitucional. Tesis: P./J. 111/2006. 
TITTLE: Constitutional dispositions in economic matter for the municipality in Mexico

RESUMEN: El diseño y disposiciones constitucionales, legales y administrativas que en materia económica se han implementado en el ámbito municipal formalmente han tenido como propósito consolidar la autonomía municipal; así como el cumplimiento eficaz y eficiente de las atribuciones encomendadas. Desde el constituyente originario en 1917 se ha tenido claro que sin suficiencia presupuestal -autonomía económica-no podría, ni podrá existir autonomía politica y administrativa; y en nuestros dias es algo que se observa con claridad meridiana por el deficiente desempeño y crisis económicas que padecen dichos gobiernos locales. La descentralización de nuevas atribuciones normativas, así como la transferencia de recursos federales, en muchos casos ha generado problemas, más que soluciones; los municipios no han correspondido con la capacidad institucional requerida-deseada. En el contexto referido la presente colaboración tiene como propósito presentar un esquema genérico de la situación económica, financiera y tributaria de los municipios mexicanos, lo anterior, a efecto de dibujar-algunas-propuestas de corte normativo $y$ administrativo que contribuyan a un mejor escenario financiero y económico de dichos entes de gobierno.

PALABRAS ClaVE: Municipio mexicano, materia económica, disposiciones constitucionales, disposiciones administrativas, autonomía municipal.

ABSTRACT: The design and constitutional, legal and administrative dispositions that in economic matter have been implemented in municipal area formally have had as intention consolidates the municipal autonomy; as well as the effective and efficient compliance of the entrusted attributions. From the original constituent in 1917 there has been had clearly that without sufficiency budget-economic autonomy-might not, there will not even be able to exist political and administrative autonomy; and nowadays it is something that is observed with crystalline clarity by the deficient performance and economic crises that the mentioned local governments suffer. The decentralization of new normative attributions, as well as the transfer of federal resources, in very many cases they have generated problems, more than solutions; the municipalities have not corresponded with the institutional needed-wished capacity. In the mentioned context the present collaboration has as intention present a generic scheme of the economic, financial and tax situation of the Mexican municipalities, the foregoing, in order to draw-some-proposals of normative and administrative kind that they contribute to a better financial and economic scene of the mentioned entities of government.

KEYWORDS: Mexican municipality, economic matter, constitutional dispositions, administrative dispositions, municipal autonomy. 